\title{
Carlos Baca Flor, primer pintor moderno y su vinculación con los artistas españoles
}

Fernando Villegas Torres ${ }^{1}$

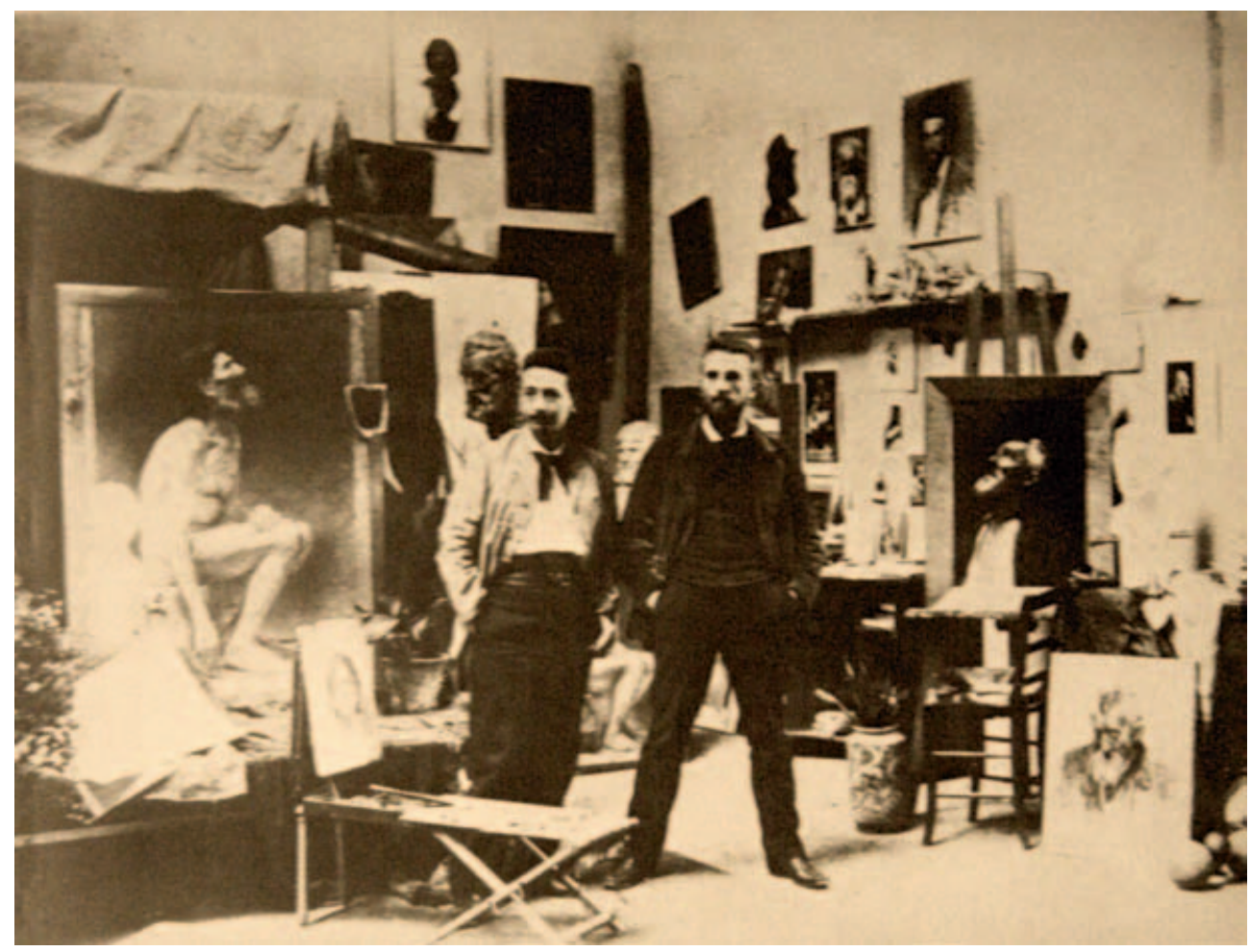

Fig.1. Carlos Baca Flor y Miguel Blay. 1892

Carlos Baca Flor es considerado por la historia del arte como el último pintor académico del arte peruano del siglo XIX. Sin embargo, poco se sabe que durante su estancia de formación en Europa el artista desarrolló una serie de acercamientos y experimentaciones que lo vinculan directamente con el arte moderno y que lo convierten en el primer pintor peruano en dialogar con las vanguardias europeas y de plantear una de las propuestas más innovadoras de su época.

En las siguientes páginas abordaremos un periodo poco estudiado del artista comprendido entre 1893-1905, en el que manifestó un acercamiento al desarrollo del arte europeo a partir de su encuentro con los artistas españoles Francisco Pradilla, Miguel Blay, Raimundo de Madrazo y Anglada-Camarasa. Consideramos que el conocer más a fondo esta etapa nos

1 El presente artículo es un avance de mi tesis doctoral La Influencia de la cultura española en la pintura y escultura peruana (1890-1929) que será presentada en el departamento de Historia del Arte Contemporáneo en la Universidad Complutense de Madrid, España, realizada gracias a la beca de estudios MAE AECID 2011-2012. 


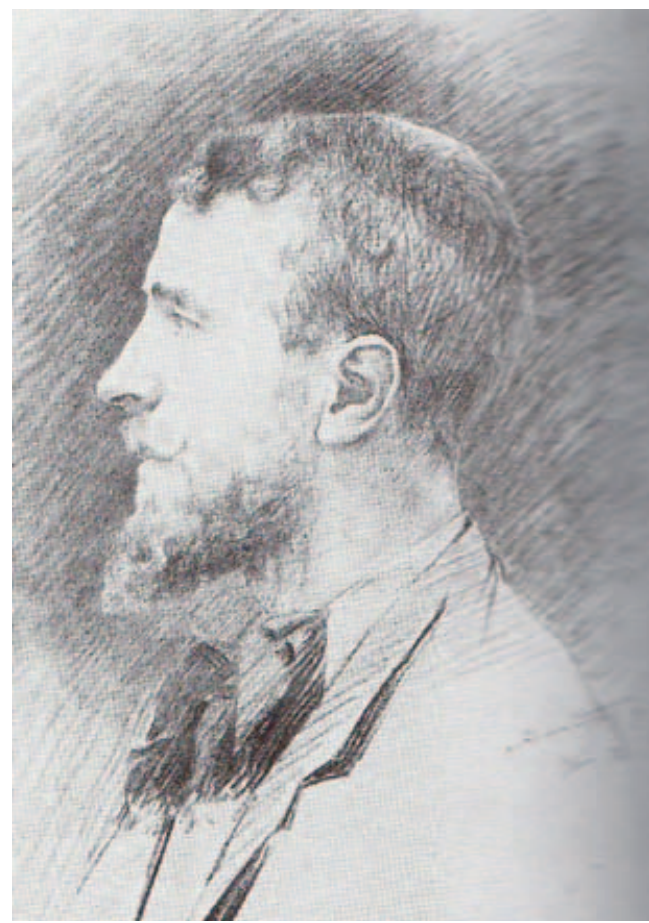

Fig.2. Retrato de Miguel Blay. Baca Flor, 1892 permitirá tener una visión más amplia y repensar la obra de tan importante pintor.

Baca Flor llegó a París a principios de junio de 1890 , permaneció en esa ciudad un mes y luego enrumbó a Roma para estudiar en la Academia de Bellas Artes (Canyameres, 1980:54). En París, además de su encuentro con el arte francés, conoció y admiró la obra del español Mariano Fortuny. Entre las diversas obras que pudo ver llamó su atención la pintura Elección de la Modelo en la que advierte la solución del trampantojo que realiza el artista en el que a través de un espejo muestra una parte del taller formando un segundo cuadro y el delicado tratamiento de los detalles del personaje así como la maña de ejecución y colorido (Jochamowitz, 1941a).

En Roma ocupó el primer lugar de los tres admitidos de un grupo de 50 concursantes ("Baca Flor, 1891:2) a la Academia de Bellas Artes y en poco tiempo se hizo de premios, como lo informa la prensa peruana:

Baca Flor. Obtuvo premio en la academia de Roma, llenando de asombro a la colonia española y a pocos sudamericanos que residen en la capital italiana. (...) tenemos ya el derecho de considerar a este peruano de veinticuatro años, como á uno de los jóvenes pintores que más probabilidades tienen de sobresalir en Europa, á fines de este siglo y á principios del próximo. (...) Le ha permitido lo que á ninguno dar dos exámenes a un tiempo a manera que no le falta ya sino un año. En la Academia Real de Roma, Baca Flor se presentó a tres concursos distintos en cada uno obtuvo el primer premio. Las medallas de oro son enviadas al gobierno por el señor Canevaro representante de Italia (“Baca Flor”, 1891:2).

Durante su estancia en esa ciudad conoció al pintor Francisco Pradilla, director de la Academia de España, a quien consideró su maestro. Pradilla era una figura internacional que había triunfado en las exposiciones de Madrid, Roma, París y Viena, considerado introductor de la pintura al pleno aire (Benet, 1980), técnica que enseñó al joven peruano y que éste utilizó en sus retratos². Baca Flor lo menciona reiteradamente en sus cartas como el único que apoyó su decisión de repetir un curso en la academia Por lo pronto, algunos creen que hago una locura someterme por segunda vez a un estudio tan árido y largo. Sin embargo, un hombre ha aplaudido mi resolución. Este es Pradilla, el cual me asegura que así tendré

2 Delboy refiere una anécdota con el pintor vinculado con la manera de hacer sus retratos, entre líneas se pone claro la búsqueda de espacio que intenta plasmar en sus obras: ¿Qué le parece?-iQué me iba a parecer sino admirable!- Y al instante, sinceramente, con toda ingenuidad, le pregunto: ¿A qué distancia le posaba el modelo? Baca Flor se alegra, me abrazo y exclama entusiasmado: iNadie, ni los criticos, me han hecho una pregunta tan inteligente! Había tocado la flauta por casualidad. Era lógico también que al admirar una pintura tan humanamente microscópica, surgiera esa interrogación. Baca Flor me dio una conferencia sobre el asunto y me explicó la importancia que tiene para el pintor. Me dijo que el retrato lo había pintado a un metro de distancia, pero que había veces que caminaba kilómetros entre el caballete y el sujeto, simplemente captando. Que otras no hacía más que conversar, observando al modelo, para trabajar después horas enteras, sin verlos (Delboy, 1941:41). La importancia del espacio en los retratos del pintor también es señalado por Canyameres Ferran (Canyameres, 1980:118). 
en mis manos un seguro y buen triunfo (Delboy, 1941:17). En otras misivas refiere que el artista español visitaba con frecuencia su estudio. Sólo Pradilla visita mi estudio con frecuencia y es entusiasta de mis ideas (Delboy, 1941:18-21). Se trata de tiempos difíciles debido a que la beca otorgada por el gobierno peruano no completó el pago acordado dejando al artista a su suerte en $1892^{3}$.

En esa misma ciudad conoce la obra Retrato del papa Inocencio X de Diego Velázquez en la Galería Doria Pamphili.

Hoy he visto a Velázquez su alma divina se ha confundido por unas horas con la mía todo desaparece ante el espectáculo que su genio ofrece. Todas mis tristezas las calma; nada hay comparable a la emoción que me produce su lenguaje. Llegué ciertamente afligido ante él, y ha devuelto todo el entusiasmo a mi alma, adormecida y sin fe. Velázquez, amigo mío y único consuelo de mis dolores (Canyameres, 1980:62-63).

En el ámbito de la Academia conoce al escultor Miguel Blay (Delboy, 1941: 25), existe una foto sobre ese feliz encuentro que tiene como fondo uno de los retratos que le hizo (1892) (Fig.1) ${ }^{4}$. En otro retrato del español realizado a lápiz (Fig.2) (Ferrés, 2001:40) Baca

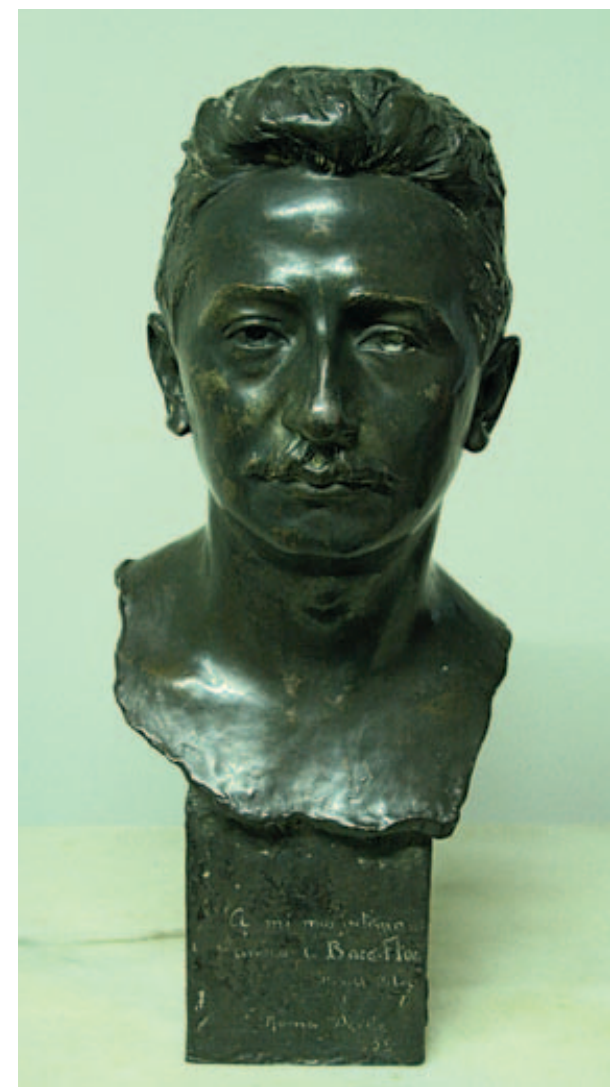

Fig.3. Busto de Carlos Baca Flor. Miguel Blay. Flor lo representa de perfil. Estos obsequios fueron correspondidos con un busto de bronce que Blay hizo de Baca Flor y que lleva la dedicación A mi más íntimo amigo C. Baca Flor Roma agosto de $1892^{5}$ (Fig.3).

El estudio de ambos artistas se encontraba cerca de la Porta del Popolo (Ferrés, 2001:40). Fue en este lugar donde Blay concibió su famoso grupo Els primers Freds (1892) ${ }^{6}$. La similitud del rostro del anciano del grupo escultórico con los pintados por Baca Flor refleja la cercanía entre los dos artistas. Incluso existe un dibujo de Blay que representa a un anciano con barba mirando hacia el cielo (Fig.4) realizado al reverso de la hoja 20 de un cuaderno

3 Carlos Baca Flor. Hace dos años el congreso le dio seis mil soles para que terminara sus estudios en Europa. Una al salir para Europa y la segunda después de dos años, vencido el plazo Baca Flor pide le den la mencionada cantidad. Incluye un certificado de la Academia de Bellas Artes (de Roma) donde consta el premio recibido por el pintor ("Carlos Baca Flor", 1891:1).

4 Este retrato lo tuvo el pintor peruano hasta su muerte. Posteriormente en 1961 sus discípulas María Luisa Faivre y Olimpia Arias lo donaron por intermedio del embajador del Perú en España Carlos Neuhaus Ugarteche a los Museos de Arte de Barcelona cuyo director era Juan Ainaud de Lasarte. Además del retrato la donación incluyó un estudio sobre la figura masculina de un grupo escultórico obra de Blay ("Aportación peruana...", 1961).

5 El busto en bronce de Carlos Baca Flor realizado por Blay se encuentra en la Casa Alegre Sagrera en Terrassa, Cataluña. En el catálogo de la colección Baca Flor adquirida por el estado peruano en 1955 y particulares se menciona un busto de bronce y el original en yeso de Baca Flor realizado por Blay ("Exposición Baca Flor", 1955:55). Actualmente se encuentran en el Museo de Arte de Lima. Se trataría de dos bustos en bronce y el original en yeso.

6 El escultor español envío dos grupos escultóricos desde Roma a la Exposición Internacional de Madrid de 1892. En el catálogo figuraban con los números 1322 Primeros Fríos (grupo yeso) y 1323 Estudio (grupo yeso). Este último sería el que recibió el primer premio, posteriormente lo denominó con el nombre del primero (Ferrés, 2001:40). 


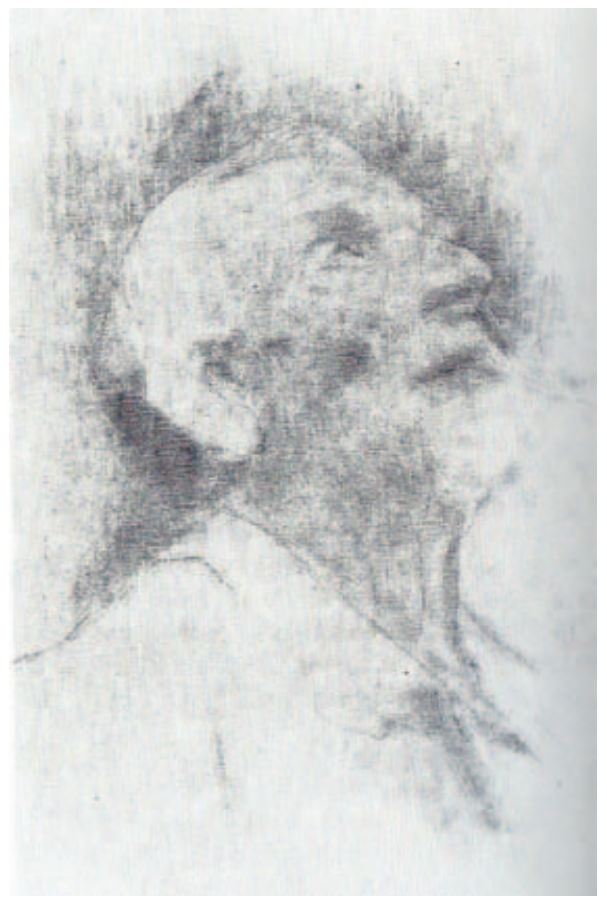

Fig.4. Retrato de anciano. Miguel Blay.

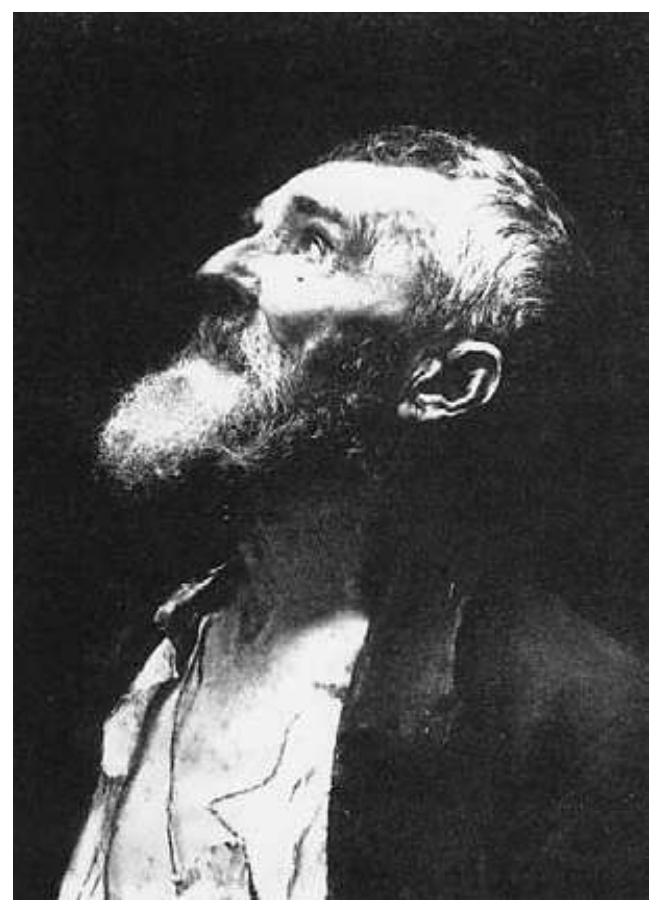

Fig.5. Cabeza de anciano. Carlos Baca Flor.

de apuntes del escultor (Ferrés, 2001:94) y que es muy similar a una cabeza de anciano de Baca Flor (Fig.5). En esta etapa también tuvo como compañeros a los pintores italianos Antonio Mancini ${ }^{7}$, el paisajista Arturo Pratella y el chileno Ernesto Molina.

\section{Entre París y Roma}

Una vez que el gobierno peruano canceló la segunda parte de su beca, y por consejo de Pradilla, Baca Flor viajó a París donde llegó el 2 de abril de 1893. Allí se matriculó en los talleres de Jean Paul Laurens y Benjamin Constant de la Académie Julien, la más reputada de las academias libres que años después tendría como alumno a Anglada Camarasa. Allí se daba instrucción en la práctica de dibujo, pintura y escultura ante el modelo desnudo. Las mujeres podían realizar estudios de desnudos, algo negado en otras academias de pintura. El fundador de la academia estableció un premio para los estudiantes ganadores de los diversos concursos que se promovían en los talleres (Jochamowiz, 1941b). Baca Flor era conocido en la academia con el seudónimo de Bacá le magnific (Delboy, 1941:54) debido a que durante el primer año ganó nueve medallas de primera clase, hecho que sólo se había dado dos veces antes (Neuhaus, 1955:29).

Como Baca Flor temía que los franceses juzgaran su obra realizada en Roma de forma negativa, no obstante señala que el entusiasmo de éstos me ha dado nueva vida. Me han llenado de esperanza y alientos. Yo desconfiaba mucho de mis estudios y del efecto que producirían en el ánimo de estos franceses, dadas las corrientes tan contrarias y absolutas de estos (Jochamowiz, 1941b).

Un incidente con su maestro Laurens lo obliga a retornar a Italia en el verano y el otoño de 1894, tiempo en el que recorrió Nápoles, Sicilia y Roma (Wuffarden, 1999:6). Es en esta etapa donde la influencia del pintor italiano Antonio Mancini se evidencia en sus retratos

7 El pintor italiano pintó al peruano dos retratos uno en 1900 y otro en 1929. Baca Flor pintó a Mancini mientras dormía en 1900 (Cayameres, 1980:81). 


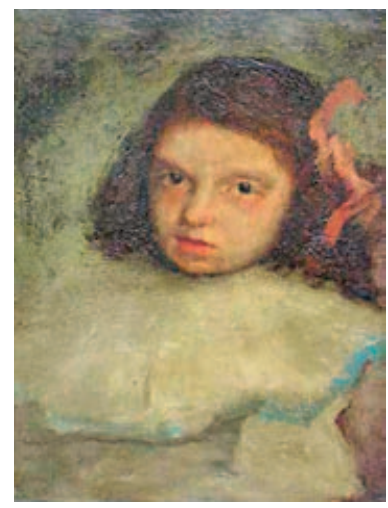

Fig.6. Retrato de niña con cinta roja. Carlos Baca Flor. 1894

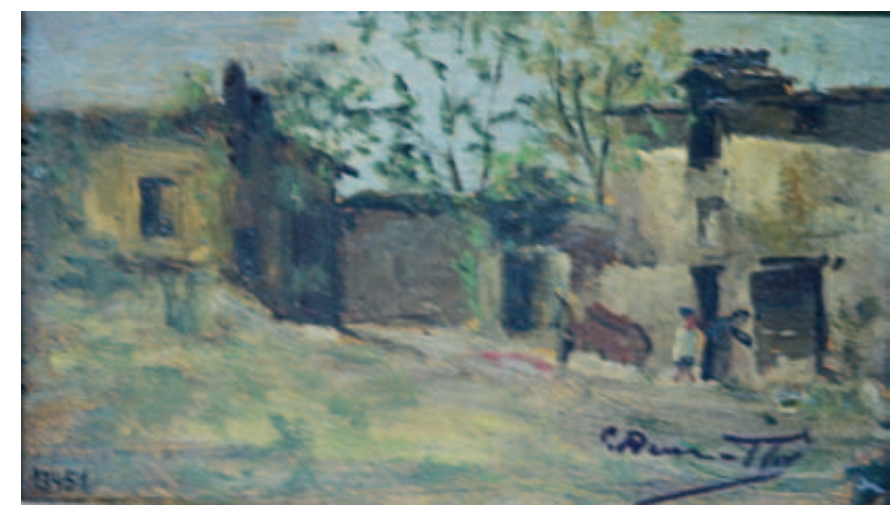

Fig.7. Paitsatge. Carlos Baca Flor. 1895.

realizados con trazos rápidos y empastes recargados, aunque todavía conserva los rostros bastante acabados.

De esta etapa son las obras Retrato de niña con cinta roja (1894) (Fig.6), Casa de Campo (1895), Paitsatge (Fig.7) y Joven de perfil (1895) que recogen cómo el artista combinó su aprendizaje de Roma y París, a través de la pincelada suelta y texturas que lo acercaban a un lenguaje más moderno. La figura del joven es de un perfecto acabado del dibujo y un conocimiento de los juegos de luces y sombras, el fondo blanco y sus matices de grises resaltan la corporeidad del retrato (Fig.8). Dos maneras de pintar colocadas en un mismo cuadro y no mezcladas. En cualquier caso muestra de manera clara los dos procedimientos que maneja el pintor.

En una carta que envía el pintor a Llona y que cita Delboy, señala que en Italia durante sus estudios en la Academia de Roma ya conoce las nuevas tendencias que se dan en arte: Sigue haciendo un relato interesantísimo sobre cómo se desarrollaban entonces -iahora también!- las exigencias del arte, así como las corrientes del modernismo con su plein air -iahora no!- que matan al desheredado (Delboy, 1941:20).

Aunque no las puso en práctica hasta 1894 después de su estadía en París. Un ejemplo de este trabajo sería aplicado al retrato, género que por excelencia practicó en todas sus etapas artísticas. El ambiente fue altamente propicio para su encuentro con el simbolismo en la galería Durand Ruel, Odilon Redon expone los Noirs. Alfred Jarry publicó el primer número de L'Imagier (Gallego, 1994:11).

En este período Baca Flor incorpora el trazo suelto y el empaste cargado en los propios rostros de los personajes que retrata, antes los limitaba solo a los fondos. En Jovencella

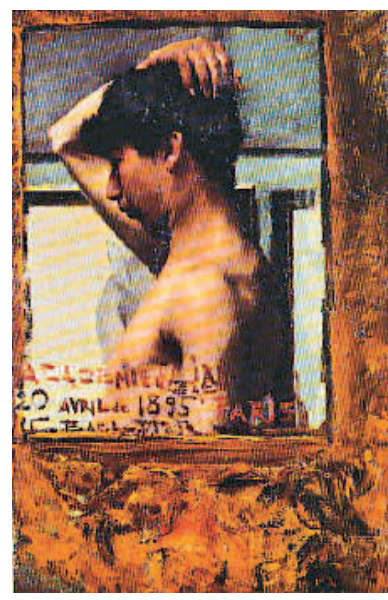

Fig.8. Joven de perfil. Carlos Baca Flor. 1895.

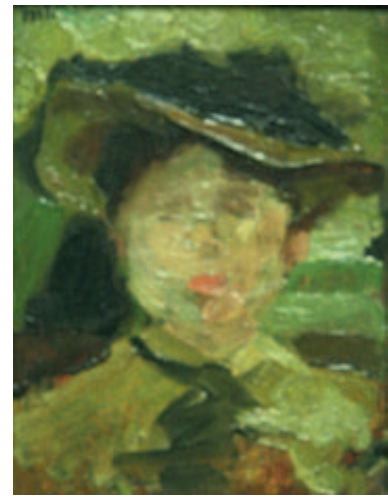

Fig.9. Jovencella. Carlos Baca Flor. 1895. (efecte del sol) (1895) (Fig.9) resuelve la pintura con la ausencia de líneas y la aplicación de colores fuertes en tonalidades verdes y amarillo, los rasgos del rostro de la joven apenas son reconocibles. En La novia (1895) ha usado el movimiento y el color para construir la vestimenta de la joven y el rostro con juegos de sombra; en El lector (1895) (Figs.10 y 11) la mano del personaje, formada por pinceladas sueltas, alude a la obra de Velázquez y el 


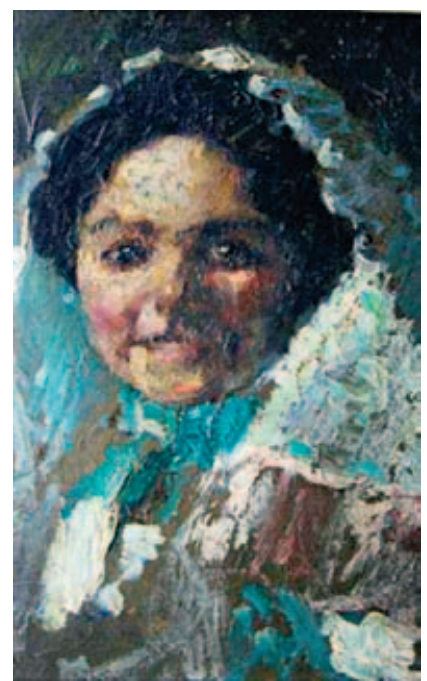

Fig.10. La novia. Carlos Baca Flor. 1895.

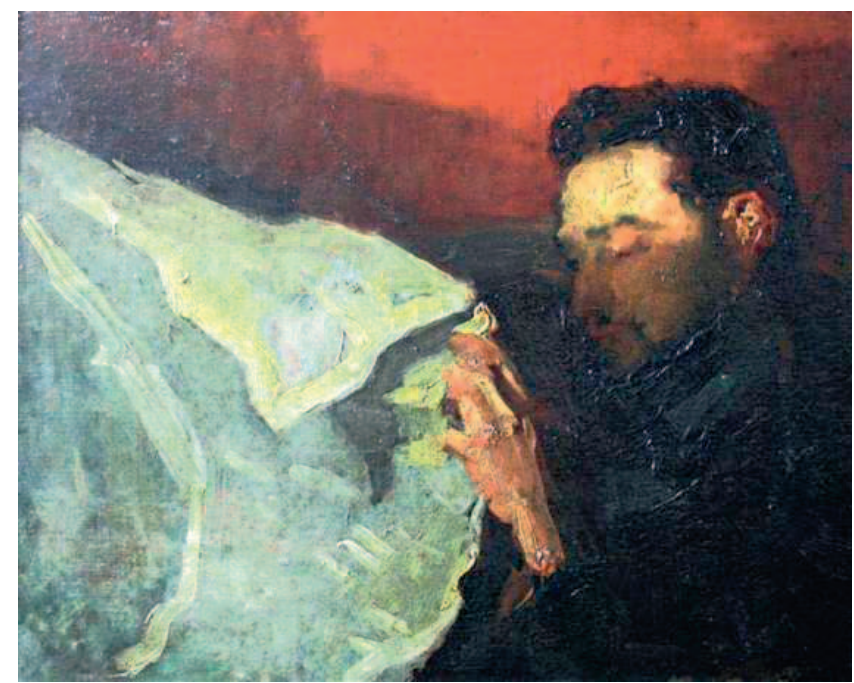

Fig.11. El lector. Carlos Baca Flor. 1895.

periódico muestra su dominio del blanco. El personaje abocetado emerge desde la sombra y el rostro apenas está compuesto por unos trazos de óleo recargado. En estas obras apenas se aprecia su aprendizaje académico.

Baca Flor sin duda vio el Retrato de Don Ramón de Errazu, e incorporó en su propia pintura ese naturalismo lleno de matices (Benet, 1980:25). Hacia 1897 registra su breve estadía en España (Canyameres, 1980:110). Fue Madrazo quién le presentó en 1895 al duque de Zoagli, Ministro del Perú en la capital francesa. Para el pintor español, se trata de un futuro Velázquez (Canyameres, 1980:102). Gracias al duque, el peruano estuvo en las fiestas del jubileo de la Reina Victoria de Inglaterra en 1897, donde pudo visitar los museos ingleses principales. El viaje a Inglaterra le permite por un lado confirmar su admiración por el gusto refinado del pintor flamenco Antón Van Dyck presente en la pintura inglesa. Esto lo tomará para sus pinturas tales como La mujer del velo (1896) y La mujer de la tanagra (1896). Estas obras son diametralmente opuestas a las reseñadas antes, es decir a los retratos modernos realizados un año antes y demuestra la complejidad de sus obras y los problemas que suscita a la hora de estudiarlas. Se trata de pinturas que se mueven en varios registros y muestran sus distintos aprendizajes. Baca Flor es un hombre de dos épocas que plasma con su pincel ese momento de transición de un siglo que no termina de irse. Admira a los clásicos universales como Rembrandt, Velázquez, Ribera, Van Dyck ${ }^{8}$ y también a los pintores modernos como Fortuny, Mancini y Sorolla ${ }^{9}$. No olvidemos que a pesar que ya conoce la técnica, se considera todavía un alumno, su afán de aprender lo hace transitar por distintos lenguajes. Su gusto conservador es fruto de su tiempo. Hacia 1894 el estado francés no quiere aceptar el legado de Gustave Caillebotte amigo y coleccionista de pintura impresionista, a pesar que esta ya había sido admitida en la Exposición Universal de 1889. Tardaron tres años en aceptar el regalo suprimiendo una docena de Pizarros por la supuesta militancia izquierdista del pintor. A demás han esperado el momento de su muerte en 1898 para que el estado francés le otorgue a Eduard Manet la legión de honor. En la exposición universal de 1900 es galardonado Joaquín Sorolla; nadie se enteró que participó Pablo Picasso con Los últimos momentos (Gallego, 1994:10-15). Todo ello indica la existencia de un ambiente artístico bastante conservador desde la oficialidad del arte y

8 Esta admiración en este período es compartida por el pintor catalán Anglada-Camarasa (Fontbona, 1994:20).

9 Niñita en Blanco (1902) de Baca Flor guarda similitudes con la obra de Joaquín Sorolla (Benet, 1980:24). Esto se hace evidente en la maestría del uso del blanco como por ejemplo Madre (1895) del pintor valenciano. 
otro vanguardista propiciado por varios artistas con sus investigaciones formales. El pintor peruano supo dialogar en ambos entornos culturales.

En 1894 conoce al artista español Hermenegildo Anglada-Camarasa en la Académie Julien y fueron grandes amigos. Fue el peruano quién intercedió ante el cuñado de Anglada, Josep Rocamora Pujolá, para que continuara apoyando financieramente al pintor cuando afrontaba una aguda crisis económica en París ${ }^{10}$. Además una de las primeras ventas de Anglada, un paisaje, fue debida a la intervención de Baca Flor ya que el comprador Roger probable pariente de su amigo Louis Roger (Fontbona, 1994:24). Fontbona señala que Anglada descubrió la plasticidad del mundo de la vida nocturna del París mundano, junto al pintor peruano, este estilo fue el que expuso en la Sala Parés entre abril y mayo de 1900 en una individual que causó gran impacto en Barcelona ${ }^{11}$ y motivó la conversión del joven Pablo Picasso a la modernidad parisina (Fontbona, 2006:16). La obra del español, hasta antes de 1897, se caracterizó por realizar paisajes y figura humana, con un cuidadoso acabado en la ejecución del dibujo. En su madurez Anglada reconoció a Baca Flor como su maestro (Fontbona, 2006: 20).

A Baca Flor, artista cuatro años mayor que el pintor catalán, le hemos de atribuir en gran parte el nuevo rumbo que tomaría la carrera artística de Anglada. Así lo reconocería él mismo en su madurez, cuando agradeció al peruano sus valiosísimos consejos que siguen siendo la base y resultado de lo poco o mucho que mi obra representa.

Anglada-Camarasa salía a pintar con Baca Flor el París nocturno: las calles, el Sena, los cafés-concierto, lo teatros; es decir, todo aquello que dio personalidad a la primera gran época parisina del catalán. En realidad, si comparamos las obras realizadas por los dos amigos en aquellas salidas nocturnas, observaremos que son muy parecidos tanto de concepto como de factura. La más antigua de las pinturas angladianas de esta temática que conocemos, en las que se destaca una figura femenina en blancos que contrasta con el fondo nocturno roto por la luz artificial que ilumina un paseo o un jardín, está fechada en 1898 (Fontbona, 1994:23).

Hacia 1899 Baca Flor también compartió clases con el pintor catalán en la Académie Colarossi ${ }^{12}$ (Fontbona, 2006:103). Allí Anglada conoció a otros dos jóvenes pintores catalanes María Pidelaserra y Pere Ysern ${ }^{13}$. Con ellos iban a pintar al matadero donde concibió uno de sus temas preferidos: los caballos (Fontbona, 1994:27). Este tema también figura en la obra del pintor peruano y es probable que compartiera clases con los pintores antes mencionados.

Cabeza de viejo o Effet de lampe (1897-98) (Fig.12) de Anglada y Cabeza de viejo (1898) de Baca Flor (Fig.13) refleja la relación entre los dos artistas. Fontbona y Miralles refieren lo antes señalado por Henry Marcel, que esta pintura fue la primera obra que expuso el español en París, aunque corrige la fecha a mayo de 1898. Los autores refieren la existencia de un carbón preparativo del óleo fechado en 1897 (Fontbona y Miralles, 1981:236). La serie de ancianos o personajes con barba, incluso desde sus años de formación en Chile pueden explicarse

10 En la nota 13, Francesc Fontbona menciona una carta que Anglada Camarasa dirige a Baca Flor fechada el 14 de octubre de 1898 donde agradece su intervención para que su cuñado le apoye (Fontbona, 1994:32). Fontbona consultó la carta en su visita al taller y archivo del pintor peruano en Neuilly Seine, cuando preparaban la monografía sobre Anglada (Fontbona y Miralles, 1981).

11 En la muestra alterno el nuevo estilo moderno iniciado en 1898 con dibujos de academia. La muestra fue un acontecimiento en la historia del arte catalán, representó de acuerdo con Alfred Opisso la aparición del neoimpresionismo. No tuvo ventas masivas pero si significativas como la de los pintores Santiago Rusiñol, Joan Llimona y el empresario vinatero Pere Grau Maristany (Fontbona, 1994:26).

12 En esta academia Anglada fue discípulo de René Prinet (Fontbona, 1994:25) Creemos por la cercanía del pintor peruano que ambos llevaron clases con el mismo profesor.

13 Entre los amigos catalanes de Anglada a parte de los dos mencionados Fontbona refiere a los artistas Eveli Torent y Manolo Hugué. Además de conocer al pianista catalán Enric Montoriol Tarrés (Fontbona, 2006:16). 
por la afición de Baca Flor a concurrir a distintas academias de pintura en Chile, Italia y Francia a su necesidad de perfeccionar su pintura ${ }^{14}$. En estos lugares era usual el uso de ancianos como modelos para estudios de pintura y cuando estuvo en Lima (1888-1890) también copió la obra de Ignacio Merino. Varias de las pinturas realizadas en los primeros años en Italia muestran estudios de ancianos como Perfil

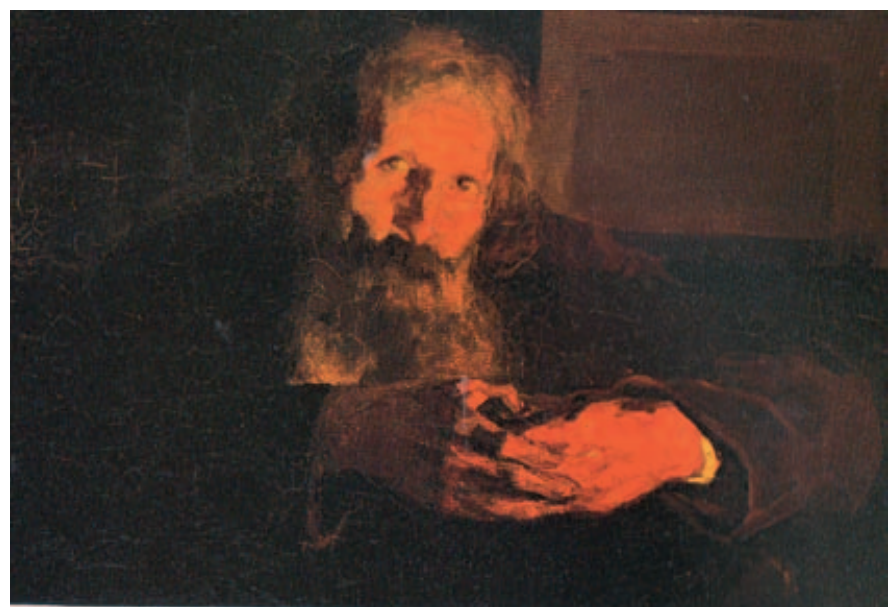

Fig.12. Effet de lampe. Hermenegildo Anglada-Camarasa. 1897-1898. (CAPSAV. de anciano (1892) al igual que los estudios que la Académie Julien de París daba a sus alumnos ${ }^{15}$. El análisis de las series de ancianos permite establecer la evolución técnica de su obra que va desde los más académicos de los dibujos hasta las propuestas más modernas en el uso del empaste cargado como el último realizado en París. Retratar un anciano enfrentaba al pintor el reto de representar texturas a través de la piel arrugada del representado. Otro de sus objetivos era la búsqueda de pintar la luz a través del contraste con las sombras siguiendo los postulados de Rembrandt como se puede ver en Retrato de Angelo (1896) donde la luz se concentra en el rostro y en la mano, lo demás se encuentra en las sombras lo que agudiza el sentido de profundidad ${ }^{16}$.

Fue Baca Flor quién dio a conocer al pintor catalán la pintura del italiano Antonio Mancini (Miralles y Fontbona, 1981). Ambos compartie-

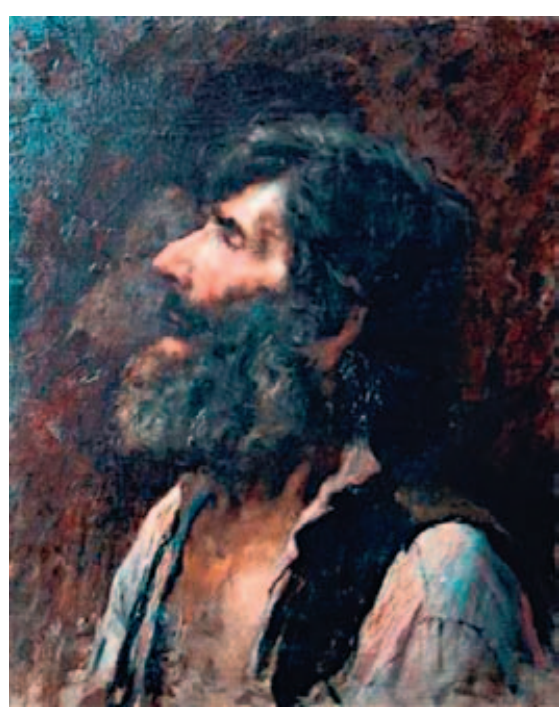

Fig.13. Cabeza de viejo. Carlos Baca Flor. 1898. ron admiración por sus obras y la manera de trabajar del italiano se incorporó en el registro técnico de sus respectivas pinturas, especialmente en el género retrato. Esto lo podemos ver en el Retrato de Georgette Leroy de López Buchardo (c. 1900) y Retrato de Josep Rocamora (1902) de Anglada y La mujer del Abanico y Mujer sentada de Baca Flor.

14 Podemos ver en el Museo Picasso de Barcelona, estudios de cabezas de viejo del joven Pablo Picasso en su período de formación.

15 Les méthodes étaient traditionnelles: copies des anciens, études d'après modèle, travail du relief par le clair-obscur, exercices sur la perspective classique (Jeancolas, $2002: 11$ ).

16 Esto aunque en su faceta académica se vio en su etapa peruana cuando pintó el retrato que consideró su Monalisa, nos referimos al retrato de Hortensia Cáceres, la figura emerge desde un fondo oscuro, la luz se irradia desde el cuerpo de la joven, concentrado en los brazos y el rostro de la joven que sobresalen sobre un fondo negro. 


\section{Baca Flor, el primer pintor moderno de Perú}

Hay que recordar que un cuadro, antes de ser un caballo de batalla, una mujer desnuda, u otra anécdota cualquiera, es esencialmente una superficie plana recubierta de colores reunidos en cierto orden. Maurice Denis, primer artículo del 30 de agosto de 1890 (Gallego, 1994:.9).

Pero existe una obra mucho más moderna que nos revela a un Baca Flor hasta ahora inédito y que permite considerarlo como el iniciador del arte moderno en el Perú. Se trata del período francés comprendido entre 1898 a 1907. Cuando el Museo de Reproducciones Pictóricas de la Universidad Nacional Mayor de San Marcos exhibió la colección Baca Flor en $1955^{17}$, un grupo de obras llamaban la atención. El público limeño conocía los retratos académicos realizados en Chile y Perú y su obra con tintes románticos con la que logró el éxito en Nueva York. Esto se manifiesta en el prefacio realizado por Alejandro Miroquezada (sic) que acompañó la muestra:

Llega, también un pintor que se renueva y que trata de expresarse de acuerdo con las modernas tendencias de su época. Cuando el artista se desliga del retrato de encargo y libremente se entrega a la plasmación de escenas, como esas deliciosas que titula del París Nocturno, o cuando el modelo es alguien que comprende las nuevas inquietudes, tal es el caso del escultor Boucher, Carlos Baca Flor realiza obras que demuestran, su estrecha vinculación con el espíritu de su época (...) he aquí el secreto de su maravillosa técnica pictórica. Y también el descubrimiento de su faceta antiacadémica, corroborada en algunas de las obras llegadas a Lima y hasta ahora desconocidas en el Perú (Miroquezada, 1955:8-10).

En la serie que Baca Flor pintó de la vida nocturna de París utilizó una estética Nabí con una paleta recargada y personajes abocetados. El color adquiere especial protagonismo resaltan los rojos y amarillos puestos directamente desde la paleta.

Las pinturas de Anglada-Camarasa y las de Baca Flor experimentaron coincidencias temáticas y técnicas. En la Foire du Trone, que presenta la feria más famosa de París, la artista de cabaret La Goulue se estrena en un barracón cuyas paredes son decoradas por telas de Toulouse Lautrec. Anglada y Baca Flor asistían a esas reuniones en la búsqueda de captar sensaciones (Gallego, 1994:11). Ambos recorrieron el París nocturno y realizaron estudios pictóricos de calles, visiones del Sena, escenas de teatro, conciertos y efectos de luces (Canyameres, 1980:106) ${ }^{18}$. Una obra con estas características es Cabezas y figuras (1902-1904) de Anglada donde las figuras son delimitadas por manchas de color, los rostros apenas reconocibles son alejados de los retratos realizados por Baca Flor desde 1894. Rafael Benet refiere al año de 1895-1898 para las pinturas que realizaron Baca Flor y Anglada sobre París.

Tal vez esa fantasía cromática encontró el origen plástico en los magistrales bocetos tan bien empastados, hechos de primera intención por el peruano por allá los años 1895-1898,

17 Gracias a la contribución del estado peruano, el apoyo de Clemente Althaus a través del recién fundado Patronato de las Artes y el aporte de los Bancos de Lima se pudo comprar la colección Baca Flor que se encontraba en París. Esta una vez en Lima se entregó en custodia al Patronato de las Artes, consistía en 86 óleos, 6 acuarelas, 192 dibujos y varias esculturas, medallas, diplomas, fotografías y otros recuerdos personales del pintor (Miroquezada, 1955:8-10).

18 Los estudios y vinculaciones de Baca Flor con Anglada Camarasa han merecido menciones en España $\mathrm{Al}$ primer trabajo de Canyameres (Agut editor, 1980) siguen los estudios sobre Anglada realizados por Francesc Fontbona y Francesc Miralles (Polígrafa, 1981). Fontbona continúo con sus trabajos sobre el pintor catalán al realizar varias exposiciones donde expone la obra de Baca Flor pertenecientes al Museo de Terrassa vinculada con la primera época en París de Anglada. En la exposición Anglada-Camarasa en el Gran Hotel redescubrir una época del 29 de julio al 31 de octubre de 1993 realizada en Mallorca figuran 10 obras del peruano, ocho pinturas: Dona asseguda en un sofá, autoretrat, Retrat Sra. B., Beatriu amb el cabell lliure, Artiste al teatre, Interior d'un café de Parísa la nit, Camí, Senyora de negre y dos esculturas titulados ambas Nu femení. En la muestra El món d'Anglada-Camarasa realizada en Barcelona del 29 de noviembre del 2006 al 18 marzo del 2007, Fontbona expuso dos cuadros de Baca Flor: Dona asseguda en un sofà (1897) y L'artista, Montmartre (1900). En Perú el Baca Flor moderno salvo lo reseñado en este texto mantiene su carácter inédito. 


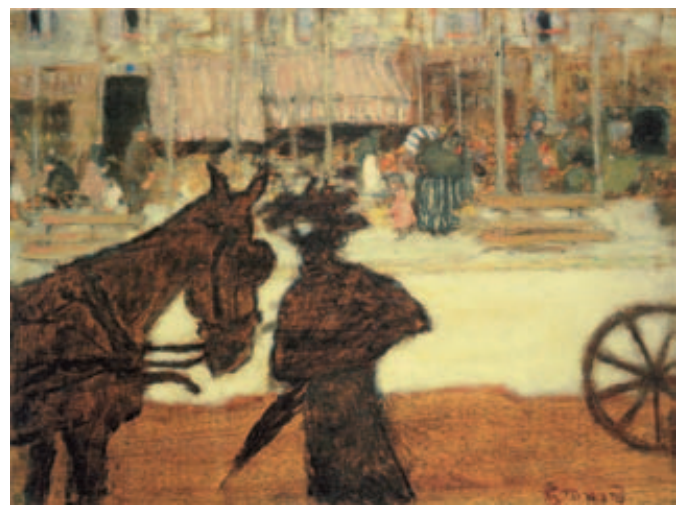

Fig.14. Effet de lampe. Pierre Bonnard. 1895. CAPSAV.

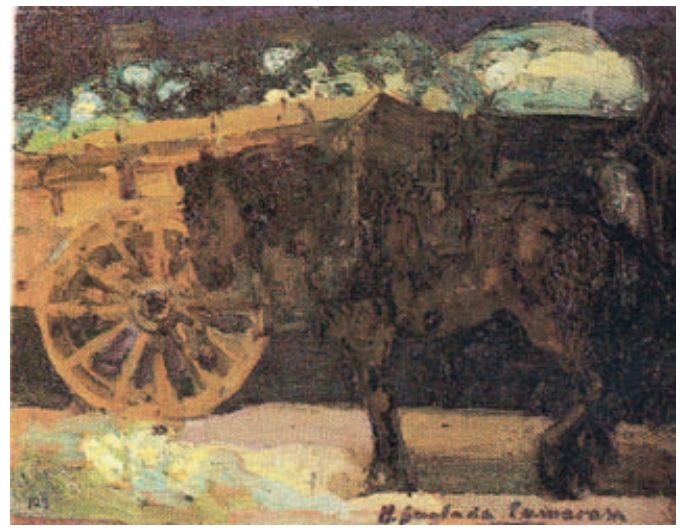

Fig.15. Caballo. Hermenegildo Anglada-Camarasa. 1901. CAPSAV.

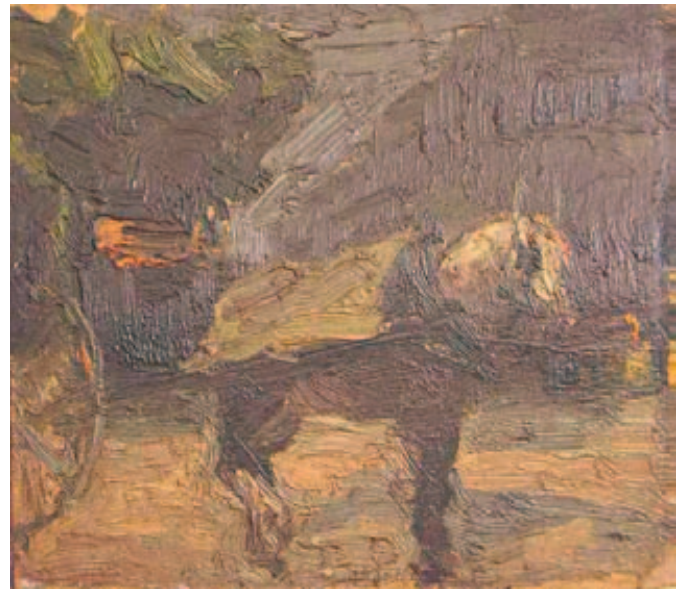

Fig.16. Caballo. Carlos Baca Flor. 1901. ante los espectáculos del París nocturno, ante los resplandores artificiales del arco voltaico que a fines de siglo irisaban la atmósfera del Moulin Rouge, del Olympia, del casino de París, del Café Anglo-Américain, de la Taverne Royale y de tantos music halls y jardines de ensueño de la Ville Lumière. Hay que recordar como nota sentimental, que Baca Flor recorría entonces estos escenarios mágicos con su amigo otro gran artista Hermen Anglada-Camarasa, quien, como es sabido, forjó su paleta en el iris de la luz artificial (Benet, 1980:20).

Fontbona y Miralles señalan que las pinturas son de 1900 aunque mencionan que los pintores se conocieron en 1897. Esta fecha coincide con la proporcionada por uno de sus principales biógrafos Canyameres Ferran ${ }^{19}$.

Como ya se mencionó en 1893 Baca Flor se encontraba en París, por ello su incursión en la pintura postimprecionista es más temprana que la del pintor catalán y las obras de 1895 muestran un lenguaje abiertamente moderno. La influencia del pintor peruano en el español es evidente en los retratos de ancianos. Aunque las obras pintadas de gusto Nabi pertenecen a su período de aprendizaje en la Academia Julien y Colarossi, más que el estudio en la academia es el medio parisino el que permite establecer una correspondencia entre ambos artistas.

Cuando Ursula Perucchi-Petri comenta las pinturas de transeúntes, caballos y carruajes de París de Pierre Bonnard se detiene en la importancia de captar el fragmento por medio del cual el estado fragmentario de las cosas era capaz de generar armonía, idea que parte de la teoría de lo grotesco formulada por Víctor Hugo. Si según Mallarmé y Valéry el todo estaba más allá de la dimensión

19 Amistad que contrajo en 1897 con el pintor catalán Hermenegildo Anglada-Camarasa: Los dos amaban por igual la pintura; los dos sentían idéntico amor hacia el trabajo. Compenetrados espiritualmente colaboraban juntos con entusiasmo; recorrían los diferentes puntos de París nocturno para efectuar estudios pictóricos: escena de la calle, visiones del Sena, escenas de teatro, de concierto, efectos de luces. Esa amistad, esta identificación duró hasta la muerte del maestro y continúa más allá incluso de la muerte (Canyameres, 1980:106). Esta amistad se prueba en una foto de las discípulas de Baca Flor con un anciano Anglada-Camarasa ya cuando el pintor peruano había fallecido reproducido en Canyameres, 1980. 


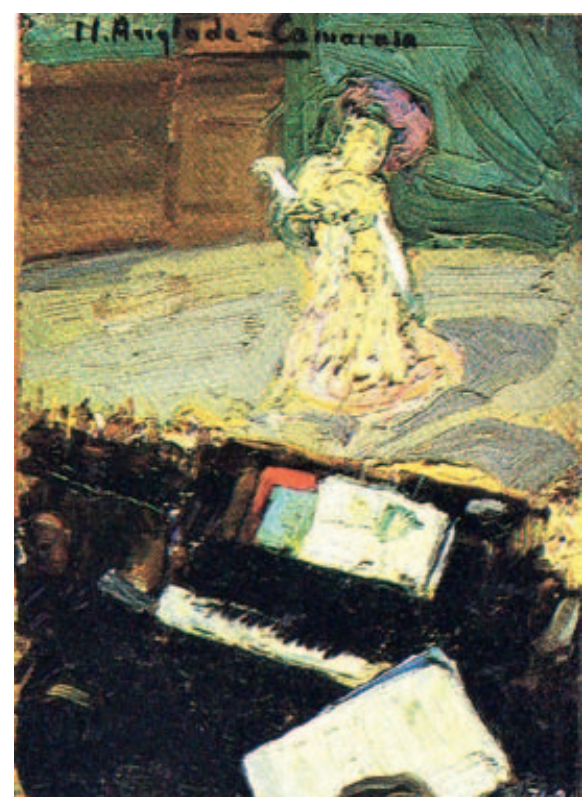

Fig.17. La cupletista. Jardín de París. Hermenegildo Anglada-Camarasa, ca.1900. (CAPSAV.

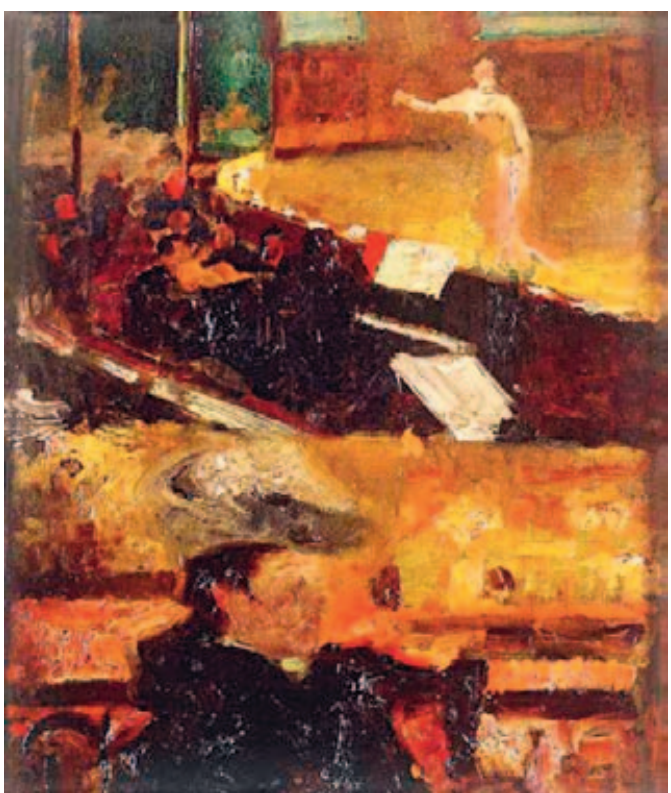

Fig.18. La cantante. Carlos Baca Flor, ca.1900.

humana, con el fragmento se podía representar lo invisible en lo visible (Petrucchi-Petri, 1993:77 ${ }^{20}$. Esta apreciación es aplicable a las pinturas de Baca Flor y Anglada realizadas en París, en las que muestran primeros planos cortados y el espacio pictórico se reduce a una escena estrecha.

Los caballos que el propio Pierre Bonnard pintó en Le chaval de fiacre (1895) ubicado en las calles de París (Fig.14) y la obra por Anglada ${ }^{21}$ (Fig.15) y Baca Flor en Caballo (1901) (Fig.16) ejemplifican esta aseveración. Otra obra donde muestran una afinidad no sólo de técnica sino de composición es La cupletista. Jardín de París de Anglada donde aparece un pianista que está junto al escenario en primer plano y una mujer con sombrero en el segundo plano (Fig.17). Baca Flor pinta la misma composición en La cantante (1900), aunque tomada desde una perspectiva más lejana que permite encuadrar más espacio ${ }^{22}$ (Fig.18).

París nocturno (1900), L’Artista. Montmartre (1900) son mucho más cercanas a la pintura de Anglada (Figs.19 y 20). Moulin Rouge. Orquesta de Anglada parece un detalle tomado de La cantante de Baca Flor.

Ambos artistas retratan a una dama de sociedad con su sombrero, utilizando como fondo la ciudad de París, tal es el caso de Interior de music hall, Paseando en el Jardín de París, Dama

20 Les éléments qui se chevauchent du sein de ses tableaux- passants, chevaux, fiacres ou roues- évoquent les palpitations de la grande ville que le peintre ne peut saisir dans son intégralité (...) Le fragment jouait déjà un rôle particulier dans la théorie du grotesque selon Victor Hugo: «L'êtat fragmentaire est propre à engendre l'harmonie» "en morcelant et en déformant la réalité extérieure, les grotesque révèle que le "grand tout» ne nous est que partiellement perceptible, car le «tout» échappe à la dimension humaine» chez Mallarmé et Valéry la notion de fragment acquiert une signification essentielle. «Le fragment constitue en art la meilleure solution possible pour représenter l'invisible dans le visible, car c'est précisément cet aspect fragmentaire qui révèle la supériorité de l'invisible et l'insuffisance du visible».

21 Fechados entre 1900-1901 Anglada pintó: Dos Caballos en espera, Caballo marrón enganchado al carro, Caballos negro, pardo y blanco, Caballos con carros de zanahorias, Estudio de caballos, Caballo blanco y negro, Caballo blanco y carro, Caballo y carro con toldo verde, Caballo con el lomo cubierto enganchado al carro y Caballo blanco enganchado en el carro (Fotbona y Miralles, 1981:240-241).

22 Se aprecia un personaje sentado en una mesa en primer plano y luego se observa a los músicos y al que toca el piano para finalizar con la mujer en el estrado. 


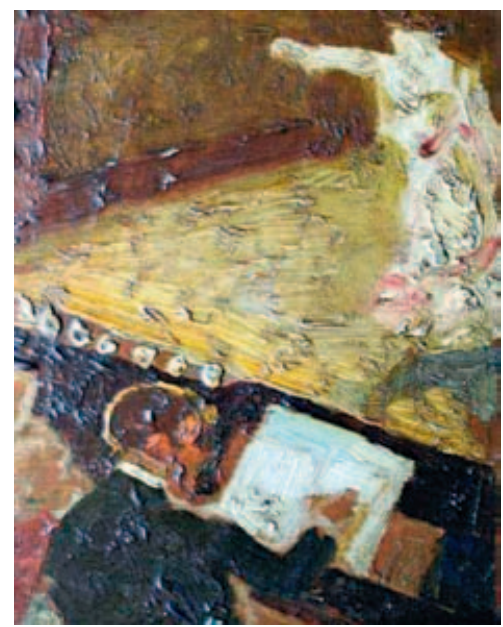

Fig.19. París nocturno. Carlos Baca Flor. 1900.

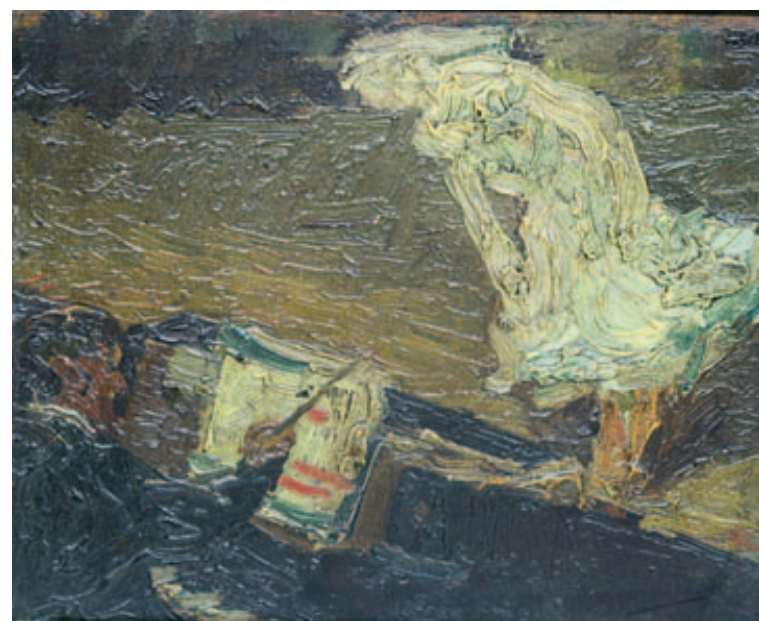

Fig.20. L'Artista. Montmartre. Carlos Baca Flor. 1900.

en un balcón, Mujeres en el palco y La loge de Anglada y las dos pinturas con el mismo nombre y fecha llamadas París Nocturno (1900) de Baca Flor (Figs.21 y 22). Por último debemos mencionar a las bailarinas de cancán representadas en París nocturno (1900) de Baca Flor y las Bailadoras de quadrille de Anglada ${ }^{23}$. Cada uno de estos cuadros nos habla de correspondencias temáticas de ambos pintores que llegaron al extremo de compartir técnicas y procedimientos de ejecución. Luis Eduardo Wuffarden fue uno de los primeros en mencionar la influencia de Édouard Vuillard en la obra del pintor peruano:

Ensaya fugazmente una interesante modalidad postimpresionista que recuerda en ocasiones a Vuillard sintética en la forma y densa en las texturas. Esta inquietud se sintetiza en la serie de vistas nocturnas de París y en el retrato del escultor Boucher, cuya amistad lo estimula para estudios de figuras vagamente rodinianas, como lo muestra el conjunto de pequeñas terracotas que guarda el Museo de Arte (Wuffarden, 1999:3).

Hacia 1889 se puede datar el debut del movimiento Nabí en torno a los jóvenes artistas quienes tenían una marcada influencia del simbolismo. Se había iniciado en 1888 cuando Paul Sérusier, a su regreso de Pont-Aven, mostró a sus condiscípulos de la academia Julien el Talismán pintado en una caja de puros; era un paisaje acuático del Bois d' Amour (Gállego, 1994:9). Se trató de una protesta al positivismo de los hombres del segundo imperio (Chassé, 1960:17).

Baca Flor pudo ver la retrospectiva de Pierre Bonnard en las galerías Durand Ruel en 1896 donde se mostró medio centenar de sus cuadros. Dos años después en la misma galería se dio un homenaje a Odilon Redon (Gallego, 1994:12-13). Esto puede explicar su vinculación con el simbolismo que se ve en Dona asseguda en un sofà (1897) donde el personaje de rostro inexpresivo es minimizado frente a los elementos de fondo que casi la envuelven. El fuerte empaste del vestido y el fondo contrastan con las tonalidades marrones usadas en la construcción del espacio u otros objetos como la araña en el techo que apenas pueden reconocerse (Fig.23). Otro ejemplo de una estética simbolista es Figura de Pizarro (1898) por la forma de pintar abocetada y difusa en la que apenas se pueden reconocer las facciones del rostro. Por primera vez en la historia del arte peruano aparece en tema histórico unido

23 Fontbona y Miralles refieren dentro del tema de los music halls el tema de las bailarinas de cancán, dibujos realizados al lápiz y carboncillo que se conservan en la colección de la fundación "La Caixa" de Palma de Mallorca. Se tratarían de búsquedas para captar movimiento (Fontbona y Miralles, 1993: 44). 


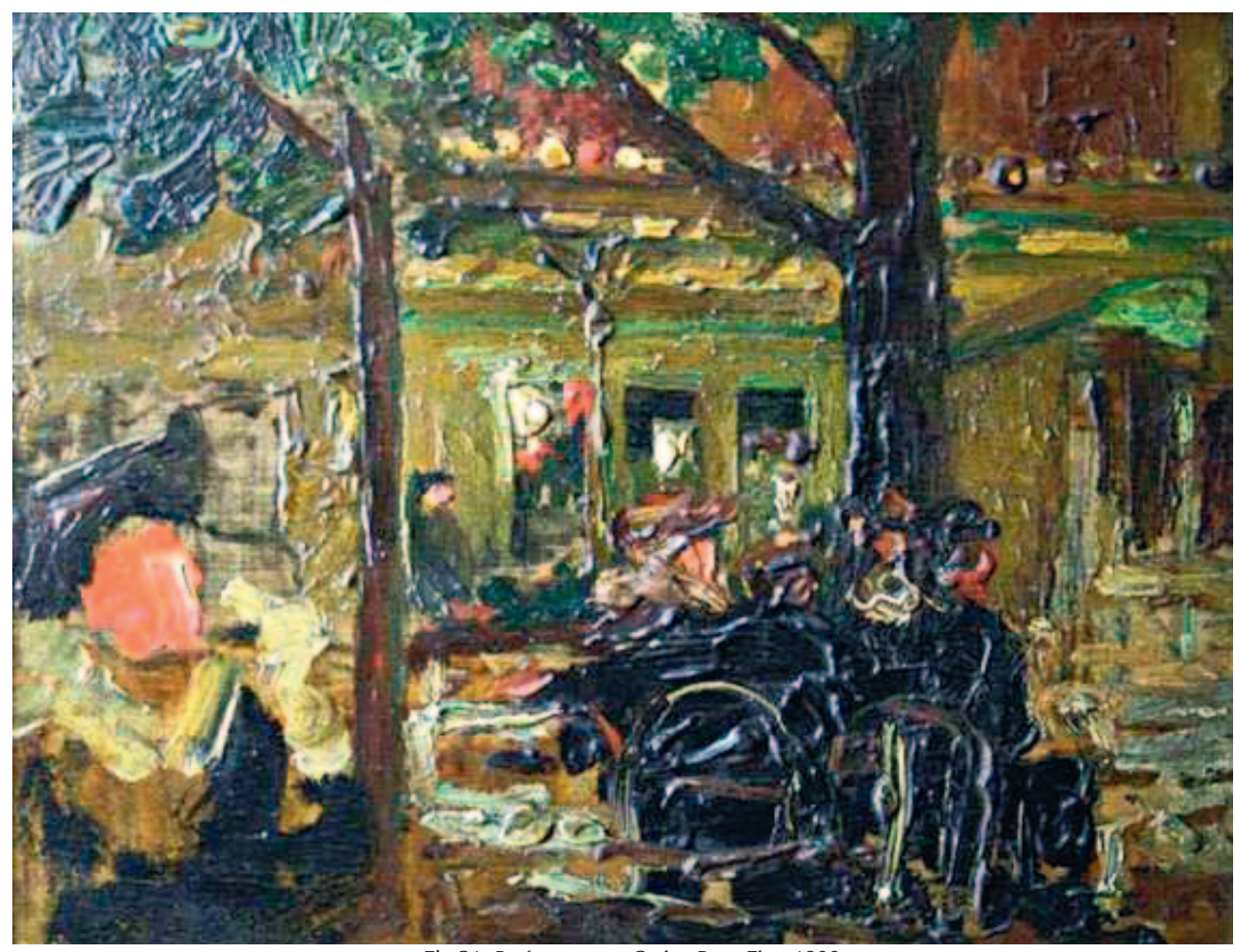

Fig.21. París nocturno. Carlos Baca Flor. 1900.

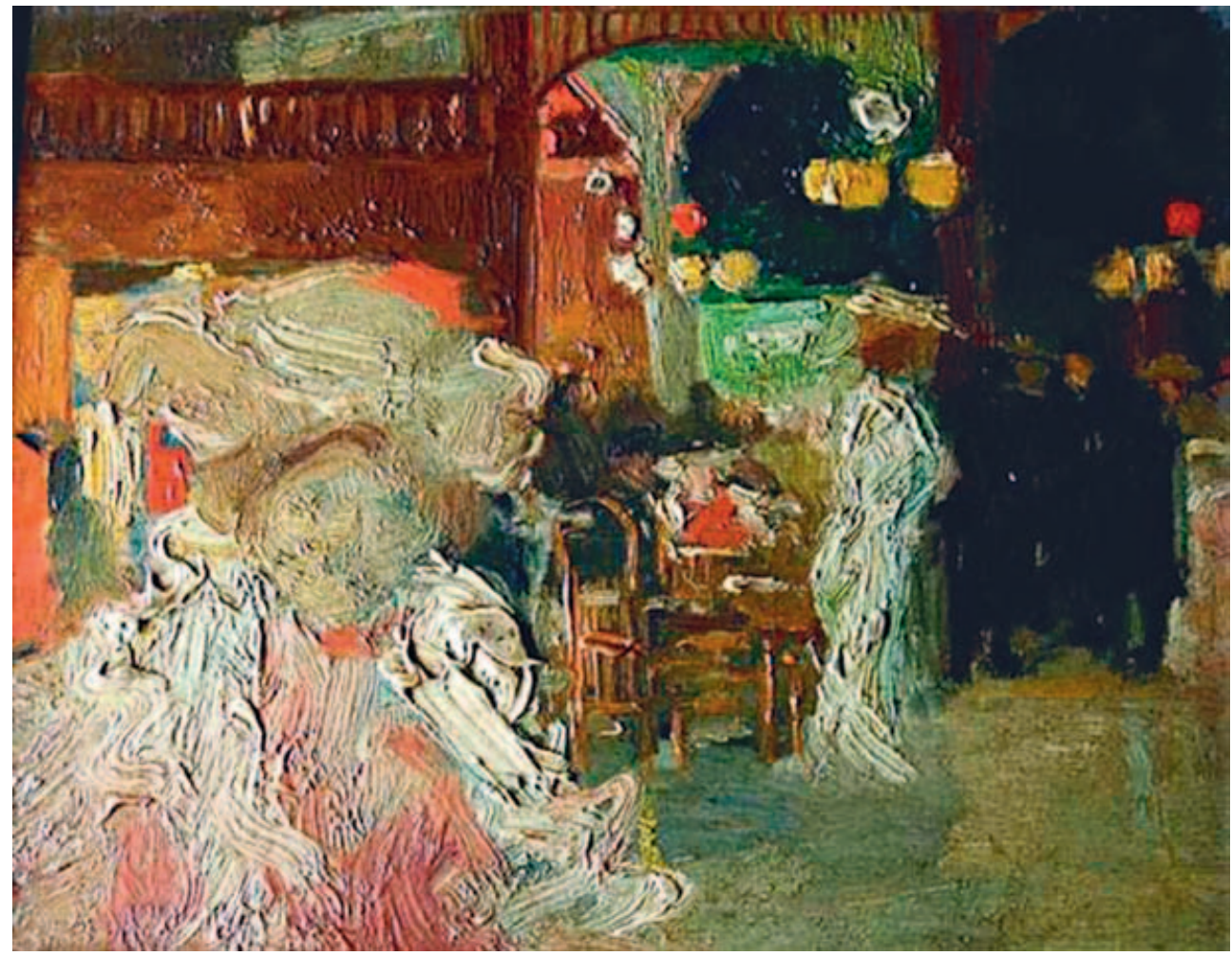

Fig.22. París nocturno. Carlos Baca Flor. 1900. 


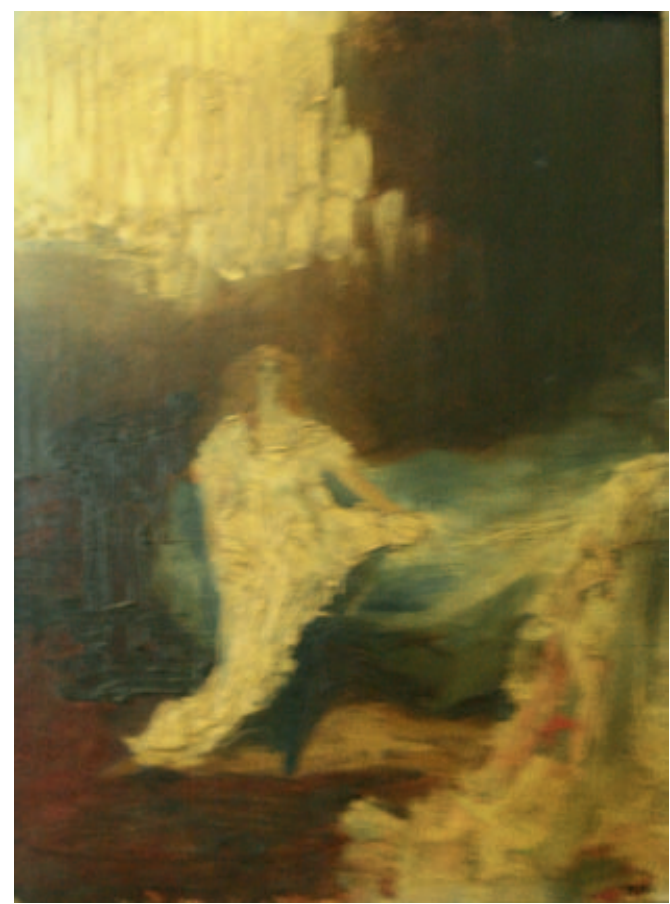

Fig.23. Dona asseguda en un sofá. Carlos Baca Flor. 1897.

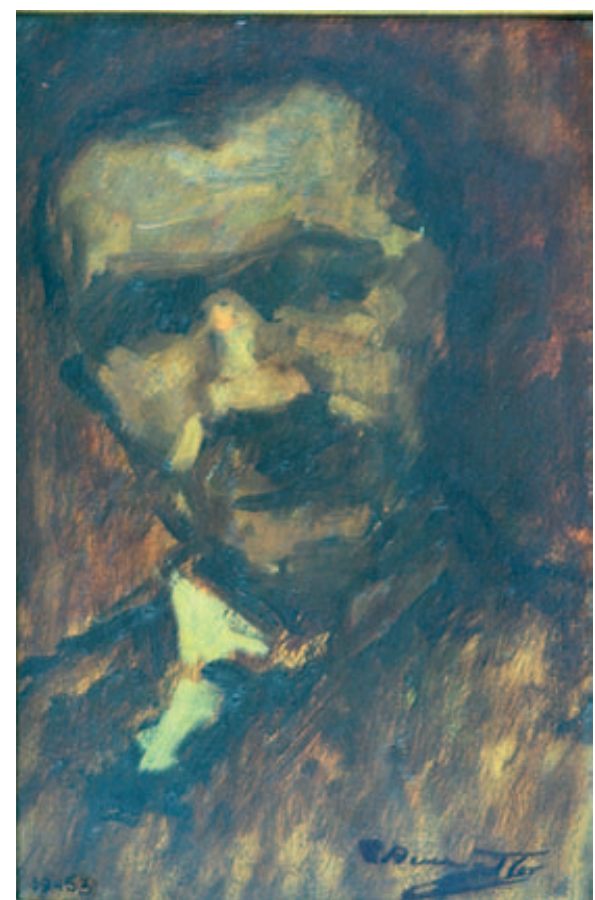

Fig.24. Cap d' hombre. Carlos Baca Flor. 1905.

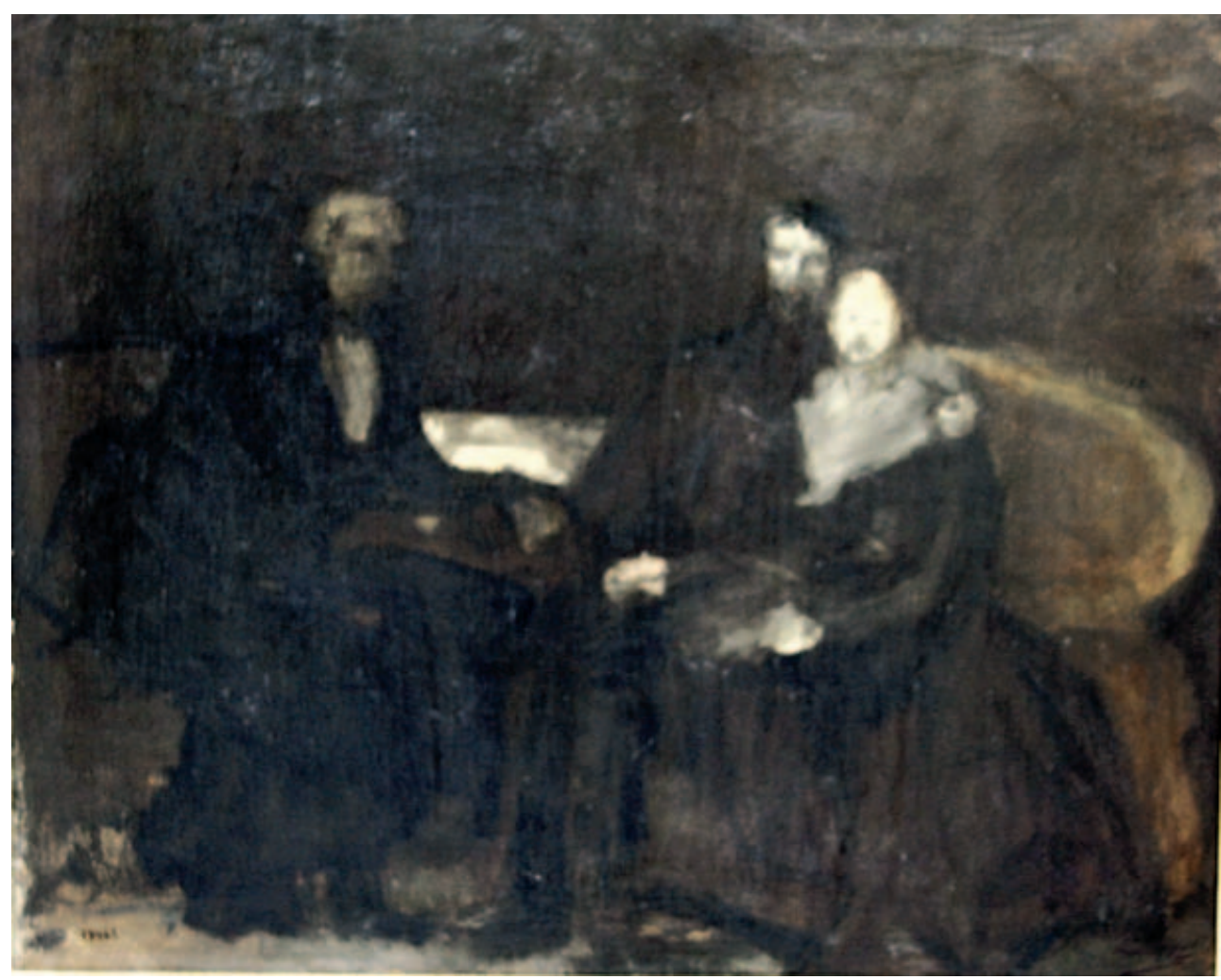

Fig.25. Composición de 3 figuras. Carlos Baca Flor. 1901. 
a la representación del arte moderno. En otros retratos como Barbut (1900) el personaje emerge desde la oscuridad del fondo o están representados con pocos trazos y sin dibujo como en Home fumant una cigareta (1900), Cap d' hombre (1905) (Fig.24) y Figura de hombre (1907). Un retrato de Anglada que guarda el mismo tratamiento técnico es Eveli Torent tocant la guitarra (1901-1904).

En Composició de 3 figures (1901) la solución se repite y el color blanco de los rostros los hace casi irreconocibles, parecen unas máscaras (Fig.25). Al parecer el artista ingresa en el terreno de la sátira de la sociedad burguesa.

En Final d' una disbauxa (1902) lo vemos siguiendo el camino de Honoré Daumier, en a que tres personajes apenas sugeridos están inmersos en un fondo verde, la calidad de la pintura y la capacidad de construir el espacio con apenas manchas de color pone a Baca Flor como una artista de primera línea (Fig.26). Similares tonos en el fondo utilizó el pintor Anglada

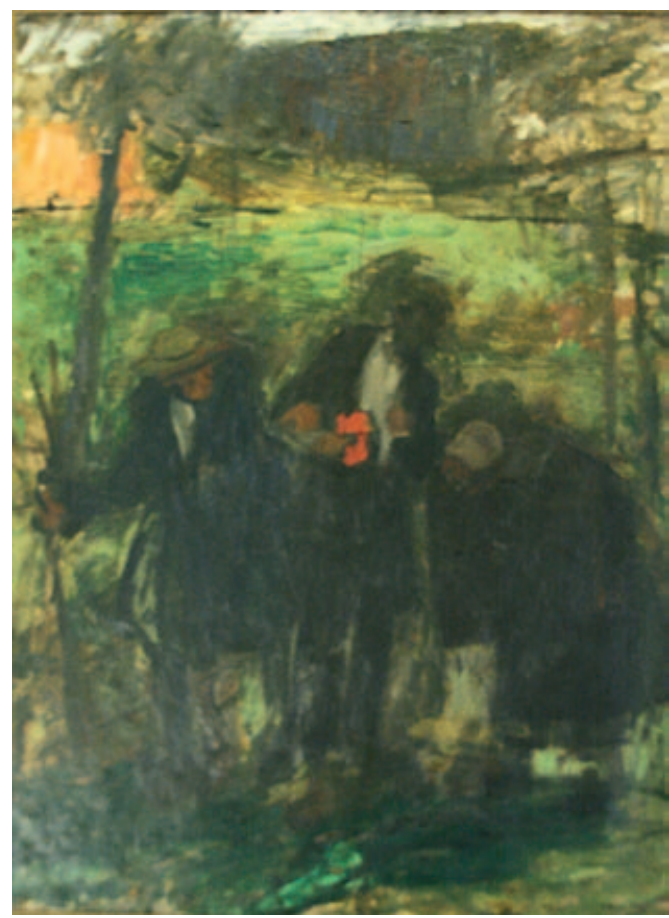

Fig.26. Final d' una disbauxa. Carlos Baca Flor. 1902. en Figures a Contrallum (1899), aunque las figuras irreconocibles parecen manchas negras.

Esto también se muestra en Cavalcant de 1905 en la que tanto la figura del personaje a caballo y el fondo son construidos con mínimos elementos no obstante los espacios son reconocibles.

En Senyora de negre (1907) ${ }^{24}$ muestra la influencia del belga Félicien Rops. El pintor hace una crítica a la sociedad burguesa a través de la dama sentada en el sofá con un rostro casi cadavérico (Fig.27).

Debemos agregar la capacidad del artista de llegar a la síntesis del retratado donde desde el simbolismo entra al terreno del expresionismo. En 1896 en las salas de L'Art Nouveau Baca Flor pudo ver las obras del expresionista Edvard Munch (Gallego, 1994:11) como se observa en Dama sentada en un sofá amarillo (Fig.28) en donde presenta a una mujer de perfil apenas reconocible. En la composición prevalece la pincelada rápida y los colores negro y blanco y el amarillo del sillón y el fondo está construido en tonalidades verdes que tienden hacia lo negro.

\section{Conclusión}

Este cuadro expresionista, los retratos simbolistas, las series de París Nocturno con su estética Nabi y el modernismo del Retrato de Jean Boucher (1901) son los mejores ejemplos de un Baca Flor moderno que sin lugar a dudas lo pone como el primer peruano en dialogar con el arte post impresionista. Los registros en los cuales desarrolla su pintura muestra la maestría del pintor para trabajar un tema tan restringido como es el retrato. El artista nos muestra las distintas maneras de concebirlo que van desde el academicismo más clásico

24 Se conserva el boceto en Dama asseguda en el Museo de Terrassa Casa Alegre Sagrera, aunque en esta primera versión el pintor prefirió representarla de perfil. 


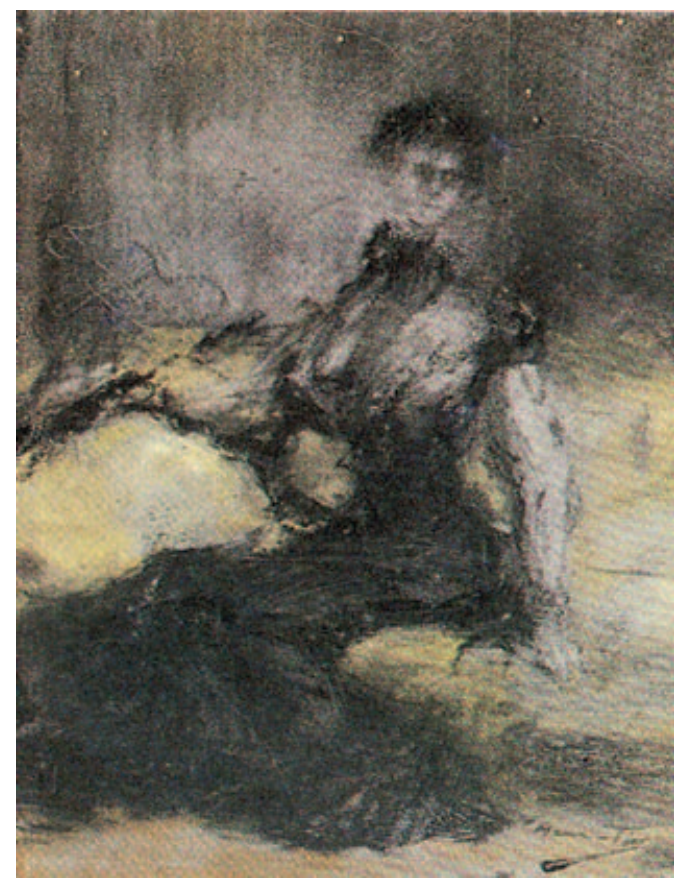

Fig.27. Senyora de negre. Carlos Baca Flor. 1907.

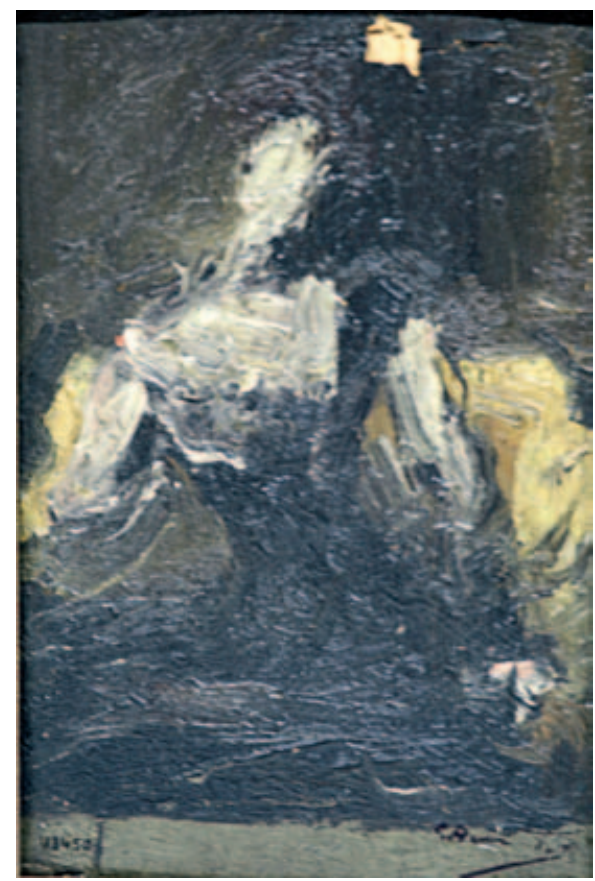

Fig.28. Dama sentada en un sofá amarillo. Carlos Baca Flor:

hasta las corrientes de la vanguardia europea de finales del siglo XIX. Sin embargo es importante señalar que no todas las tendencias del arte moderno le fueron afines al pintor. Le fue indiferente por ejemplo la propuesta puntillista de Paul Signac quien intentó establecer reglas para el arte en De Delacroix au Néo-Impressionnisme (1899), la estética naif de Rousseau o las lecciones futuristas y cubistas. Tal vez más afín por la prevalencia del color en este período son los fauves quienes hacían su presentación en el salón de otoño de 1905 . Aunque con una diferencia importante Baca Flor derivaba el uso del color de su tendencia hacia el simbolismo mientras a los fauves les interesaba aplicar el color directo sobre la tela, aparentemente alejados de miradas introspectivas.

Hacia 1904 las propuestas de Baca Flor y Anglada-Camarasa empezaron a bifurcarse. El catalán realizó sus acostumbradas representaciones femeninas y la última obra modernista del peruano fue el proyecto del Monumento a San Martín presentado con el seudónimo Liberté, égalité, fraternité que no llegó a ganar en el concurso realizado en Perú en 1905 (Villegas, 2010:218). Con este monumento se cierra la etapa más rica y productiva del pintor peruano aquella en la que realizó diversos estudios de artistas tanto antiguos como contemporáneos y en la que se dejó seducir por el espíritu renovador del arte europeo.

Hacia 1907, Baca Flor decidió por primera vez exponer una de sus obras en el salón de París, El retrato del Conde Jean Chavanne de la Pallise en traje de caza y consiguió el triunfo académico al ser premiado con medalla de honor y así se le encargó el Retrato del Modisto Worth (Cayameres, 1980:129). Lo que sigue es historia conocida, a partir de ahí, su fama como retratista lo hizo abandonar su etapa modernista, Nabí, expresionista y simbolista para realizar retratos realistas y académicos del mundo empresarial neoyorkino. El viaje a Estados Unidos en septiembre de 1909 representó un cambio y a la vez marcó el final de la etapa más rica de búsquedas del primer pintor moderno del Perú. 


\section{Bibliografía}

"Aportación peruana al Museo de Arte Moderno"

1961 La Vanguardia Española, Barcelona, noviembre 28.

"Baca Flor"

1891 El Comercio, Lima, abril 3, p.2.

\section{BENET, Rafael}

1980 "La pintura de Baca Flor vinculada con su tiempo" En Canyameres Ferran, Carlos Baca Flor, Barcelona, Agut Editor.

CANYAMERES, Ferran

1980 Carlos Baca Flor, Barcelona, Agut Editor.

"Carlos Baca Flor"

1891 El Comercio, Lima, diciembre 15, p.1.

\section{CHASSÉ, Charles}

1960 Les Nabis et leur temps. París, La biblioteque des Arts.

DELBOY, Emilio,

1941 Carlos Baca Flor. Dos crónicas y una charla. Lima, San Martí S.A.

FERRÉS, Pilar

2001 Miguel Blay i Fàbrega 1866-1936 La escultura del sentimiento, Girona, Marquès Tallers Gràfics.

\section{GALLEGO, Julián}

1994 "El París de Anglada-Camarasa", En El París de Anglada-Camarasa, Policrom, Generalitat de Catalunya, Fundación la Caixa.

JEANCOLAS, Claude

2002 La peinture des Nabis, París, FVW édition.

JOCHAMOWITZ, Alberto

1941a "Baca-Flor hombre singular", Cultura Peruana, Lima, № 3 , julio.

1941b "Baca-Flor hombre singular", Cultura Peruana, Lima, $\mathrm{N}^{\circ} 4$, septiembre.

FONTBONA Francesc y MIRALLES Francesc

1981 Anglada Camarasa, Barcelona, Polígrafa.
1993 "La colección Hermen Anglada-Camarasa de la Fundación La Caixa”, En AngladaCamarasa en el Gran Hotel redescubrir una época, Barcelona, Fundación La Caixa Illes Balears.

\section{FONTBONA Francesc}

1994 "Anglada- Camarasa. Itinerario biográfico de su primera época de París (18941904)", En El París de Anglada-Camarasa, Policrom, Generalitat de Catalunya, Fundación la Caixa.

2006 "Anglada- Camarasa y su mundo", En El món d'Anglada- Camarasa, Barcelona, Caixa Forum Barcelona, Agpograf.

\section{MIROQUEZADA, Alejandro}

1955 "Prefacio", En Catálogo Exposición Baca Flor óleos, acuarelas, dibujos, esculturas, recuerdos personales, Lima, Museo de Reproducciones Pictóricas UNMSM y Patronato de las Artes.

\section{NEUHAUS, Carlos}

1955 "Discurso del presidente del Patronato de las Artes", En Catálogo Exposición Baca Flor óleos, acuarelas, dibujos, esculturas, recuerdos personales, Lima, Museo de Reproducciones Pictóricas UNMSM y Patronato de las Artes.

PERUCCHI-PETRI, Ursula

1993 “"Le paysage des grandes villes» Rues, places et jardins publics", En Nabis 18881900, París, Spadem, Adagp, pp.75-103.

\section{VILLEGAS, Fernando}

2010 "La escultura en el 900: entre la obra europea importada y la formación de la escultura nacional", Revista del Museo Nacional, T. L, Lima, pp.211-245.

WUFFARDEN, Luis Eduardo

1999 Catalogo Baca Flor obras maestras, Arequipa, Fundación del Banco Continental, Museo de Arte de Lima, Agosto-septiembre. 